Int. J. Electrochem. Sci., 16 (2021) Article ID: 210549

International Journal of

ELECTROCHEMICAL

SCIENCE

www.electrochemsci.org

\title{
Current Distribution of Lead Ions Deposition Within Porous Flow-Through Electrodes Operating Under Simultaneous Hydrogen Gas Evolution
}

\author{
Mohamed S. El-Deab ${ }^{1, *}$, Mohamed I. Awad ${ }^{1,2}$, Aya Md. Saada ${ }^{3}$ and Attia M. Attia, ${ }^{4, *}$ \\ ${ }^{1}$ Chemistry Department, Faculty of Science, Cairo University, 12613 Cairo, Egypt \\ ${ }^{2}$ Chemistry Department, Faculty of Applied Science, Umm Al-Qura University, Makkah, KSA \\ ${ }^{3}$ Biochemical Engineering Department, Faculty of Energy and Environmental Engineering, The \\ British University in Egypt (BUE), El Shorouk City, 11837, Cairo, Egypt \\ ${ }^{4}$ Petroleum Engineering and Gas Technology Department, Faculty of Energy and Environmental \\ Engineering, The British University in Egypt (BUE), El Shorouk City, 11837, Cairo, Egypt \\ "E-mail: msaada68@yahoo.com (M. S. El-Deab), attia.attia@bue.edu.eg (Attia M. Attia).
}

doi: $10.20964 / 2021.05 .51$

Received: 15 October 2020 / Accepted: 24 December 2020 / Published: 31 March 2021

This study addresses the impact of operating hydrodynamic and structural parameters affecting the distribution of metal deposition current within flow-through porous reactors, i.e., the electrolyte resistivity $\left(\rho_{\text {eff }}\right)$ and flow rate $(v)$ as well as the electrode thickness $(L)$ of the porous bed. Measurements are performed on the distribution of the lead deposition reaction within packed bed electrodes composed of stacked screens, with simultaneous hydrogen evolution (as a parasitic side reaction). The uniformity of the current distribution is found to increase with the decrease of the electrolyte resistivity and/or increase of electrolyte flow rate, while increase of the electrode thickness results in a less uniform current distribution. The results are explained in the light of the existing electrochemical theory, in which a dimensionless ohmic index, $\xi\left(=i_{\text {cell }} \rho_{\text {eff }} L / b\right.$ where $i_{\text {cell }}$ is the cell current and $\left.b=R T / F\right)$ is developed. Larger values of $\xi$ produce less uniform current distributions with less than $10 \%$ of the entire thickness of the porous bed is in effective use. Whereas, higher electrolyte flow rates sweeps away the generated gas bubbles, thus, causes a marked decrease of $\rho_{\text {eff }}$ by decreasing the fraction of the trapped hydrogen gas bubbles within the electrode and hence lead to more uniform current distributions.

Keywords: Porous reactors, Gas evolving electrodes, Heavy metals, Wastewater treatment.

\section{FULL TEXT}


(C) 2021 The Authors. Published by ESG (www.electrochemsci.org). This article is an open access article distributed under the terms and conditions of the Creative Commons Attribution license (http://creativecommons.org/licenses/by/4.0/). 